\title{
Well-being dynamics and poverty traps
}

Christopher Barrett, Teevrat Garg and Linden McBride

\author{
January 2016
}

Centre for Climate Change Economics and Policy Working Paper No. 250

Grantham Research Institute on Climate Change and the Environment Working Paper No. 222 
The Centre for Climate Change Economics and Policy (CCCEP) was established by the University of Leeds and the London School of Economics and Political Science in 2008 to advance public and private action on climate change through innovative, rigorous research. The Centre is funded by the UK Economic and Social Research Council. Its second phase started in 2013 and there are five integrated research themes:

1. Understanding green growth and climate-compatible development

2. Advancing climate finance and investment

3. Evaluating the performance of climate policies

4. Managing climate risks and uncertainties and strengthening climate services

5. Enabling rapid transitions in mitigation and adaptation

More information about the Centre for Climate Change Economics and Policy can be found at: http://www.cccep.ac.uk.

The Grantham Research Institute on Climate Change and the Environment was established by the London School of Economics and Political Science in 2008 to bring together international expertise on economics, finance, geography, the environment, international development and political economy to create a worldleading centre for policy-relevant research and training. The Institute is funded by the Grantham Foundation for the Protection of the Environment and the Global Green Growth Institute. It has nine research programmes:

1. Adaptation and development

2. Carbon trading and finance

3. Ecosystems, resources and the natural environment

4. Energy, technology and trade

5. Future generations and social justice

6. Growth and the economy

7. International environmental negotiations

8. Modelling and decision making

9. Private sector adaptation, risk and insurance

More information about the Grantham Research Institute on Climate Change and the Environment can be found at: http://www.Ise.ac.uk/grantham.

This working paper is intended to stimulate discussion within the research community and among users of research, and its content may have been submitted for publication in academic journals. It has been reviewed by at least one internal referee before publication. The views expressed in this paper represent those of the author(s) and do not necessarily represent those of the host institutions or funders. 


\title{
Well-Being Dynamics and Poverty Traps
}

\author{
Christopher B. Barrett \\ Cornell University \\ Teevrat Garg \\ Grantham Research Institute on Climate Change and the Environment, \\ London School of Economics and Political Science \\ and \\ School of Global Policy and Strategy, \\ University of California, San Diego \\ Linden McBride \\ Cornell University
}

January 2016 draft

Prepared for invited submission to the Annual Review of Resource Economics, volume 8 (2016).

Keywords: chronic poverty, development, market failures, multiple equilibria, safety nets

Acknowledgements: We thank Geoff Barrows, Leah Bevis, Larry Blume, Michael Carter, Sommarat Chantarat, Jean-Paul Chavas, Paul Christian, Brian Dillon, John Hoddinott, David McKenzie, Hope Michelson, and Russell Toth for helpful comments and discussions that have shaped our thinking, without implicating them for any errors that might remain. Garg acknowledges funding from ESRC Centre for Climate Change Economics and Policy and the Grantham Foundation for the Protection of the Environment. 


\begin{abstract}
A sound understanding of poverty traps-defined as poverty that is self-reinforcing due to the poor's equilibrium behaviors - and their underlying mechanisms is fundamentally important to the development of policies and interventions targeted to assist the poor and/or eradicate poverty. We review the theoretical and empirical evidence on single and multiple equilibria poverty traps at the macro, meso, and, especially, micro levels. In addition we review the literature exploring the various mechanisms that have been posited to perpetuate poverty. We find sufficient evidence to support the poverty traps hypothesis, suggesting that policies designed to interrupt those self-perpetuating mechanisms merit serious attention.
\end{abstract}

\title{
1 Introduction
}

The world has witnessed historically unprecedented rates of escape from poverty over the past generation (Chen \& Ravallion 2010, Ravallion 2013). At the same time, the most severe forms of human deprivation - often lumped under the shorthand of 'ultra-poverty' - have grown more spatially concentrated, especially in rural sub-Saharan Africa and in a few pockets of rural South Asia, and appear remarkably persistent (Barrett 2014). The increased recognition of concentrated, persistent, ultra-poverty has rekindled longstanding scholarly interest in poverty traps, which arise when poverty becomes self-reinforcing due to behaviors that perpetuate low standards of living.

At the same time, panel data sets that observe the same individuals or households over time have become more plentiful, especially in developing countries. Because the study of economic dynamics requires data that track economic units - individuals, households, countries, etc. - over time, the emergence of panel data has opened up areas of micro-level study of well-being dynamics that were infeasible a generation ago. The combination of rekindled research interest and newly feasible empirical inquiry has sparked a vibrant line of research around well-being dynamics and poverty traps over the past decade or so. This paper summarizes the essence of that literature.

Research on poverty traps focuses on understanding why some people, communities, and even entire nations remain mired in grinding poverty while others have enjoyed rapid improvements in standards of living. The hope is that an improved understanding of such heterogeneous well-being dynamics can help inform the design of interventions that might put individuals, households, and nations on a more favorable trajectory out of poverty and towards sustainably higher standards of living. Because "poverty" is an elusive concept, the literature mixes various measures of well-being based on flows of income or expenditures with measures of assets and/or human education, health, or nutritional status. But the essence of the problem is invariant to the particular well-being indicator used.

The poverty traps hypothesis is especially important because of its policy implications. Where no poverty trap exists, poverty is necessarily a transitory phenomenon, although it 
may take a painfully long time to resolve, especially if bad luck strikes frequently. This transitory poverty can arise due to short-term adverse income shocks to a non-poor expected standard of living - what Carter \& May 2001 term 'stochastic poverty'. But it can also be associated with steady improvements anticipated from equilibrium investment patterns that lead to structural escapes from poverty. Given the cost inherent to interventions - not least of which due to the general equilibrium welfare losses associated with taxation and administration - and the ever-present risks of failure, interventions aimed at accelerating the escape from intrinsically transitory poverty face a formidable burden of proof as to their likelihood of delivering net positive returns to society. Many empirical studies of household income dynamics in developing countries find that a very large proportion of poor households move in and out of poverty over short periods of time, implying that most poverty is transitory (Baulch \& Hoddinott 2000). If that is generally true, the policy argument for intervention becomes harder to make.

By contrast, when poverty persists indefinitely in the absence of intervention such that expected standards of living at any reasonable time horizon are below a poverty line, a poverty trap exists, and the case for intervention becomes far stronger. Initiatives that could move people out of a poverty traps such as interventions to induce investment in or protection of productive assets, adoption of improved production technologies, participation in more remunerative markets, entrepreneurial risk-taking, and so on attract particular interest because they are seen as opportunities for short-term interventions to precipitate permanent changes in well-being trajectories. In the presence of (at least some forms of) a poverty trap, poverty appears unnecessary and avoidable, making response ethically compulsory and economically attractive. Therefore, it matters greatly from a policy perspective whether the poverty traps hypothesis is true.

\section{Conceptualizing poverty traps}

The dynamics of poverty arise naturally from the coupled dynamics of asset accumulation and technology adoption in the face of risk and uncertainty. In this framework, 'assets' are broadly defined as the state/stock variables used to generate income, including future income against which one might borrow. This includes both public and private goods and encompasses financial, human, natural, and social capital. Technologies map stocks of assets (e.g., land) and flows of inputs (e.g., labor) into flows of income or other goods or services of value (e.g., time with friends). This encompasses both production and exchange technologies (i.e., market and non-market means of transacting) and the institutions that support them. Risk and/or Knightian uncertainty surround both asset stocks (i.e., their laws of motion) and technologies (e.g., prices, yields).

The initially poor can readily grow their way out of poverty if they accumulate productive assets or adopt more remunerative exchange or production technologies that increase future income. In a textbook world with complete and competitive markets, the poor have strong incentives to accumulate and adopt. These dynamics underpin neoclassical economic growth theory and its familiar prediction of convergence towards a unique, dynamic equilibrium rate of steady state growth in well-being (Barro \& Sala-i-Martin 2004). But when poor initial conditions - commonly manifest in meager asset holdings and the use of relatively inefficient production or exchange technologies - instead induce behaviors that reinforce 
poverty, convergence might not occur. Then the prospect of a poverty trap acquires particular salience.

Poverty traps can arise through any of a host of structural mechanisms reviewed in this section. These mechanisms can exist - and co-exist - at macro, meso and micro scales of analysis. At the macro scale, institutional, geographic, and coordination/technology failures can conspire to trap countries and regions in poverty. At the meso scale, social networks and norms can exclude households and individuals from growing their capital and productive assets or from accessing credit (Chantarat \& Barrett 2011, Mogues \& Carter 2005, Santos \& Barrett 2011). At the micro scale, a range of mechanisms discussed below can render poverty self-reinforcing (Azariadis \& Stachurski 2005, Bowles et al. 2006). Poverty traps can also arise as a mutually reinforcing combination of all three scales in what has been dubbed a fractal poverty trap (Barrett \& Swallow 2006).

In the simplest case of a single equilibrium poverty trap, an economic unit - individual, household, country, etc. - converges on a unique dynamic equilibrium, per canonical growth theory; but that equilibrium falls beneath the poverty line. Such a situation can arise from rudimentary feasible technologies conditional on the unit's (quasi-)fixed characteristics (Barrett \& Carter 2013a). Differences in structural characteristics may give rise to what the macroeconomic growth literature calls "club convergence", the idea that specific units identifiable by a shared structural characteristic - a "club" - all converge over time on the same unique level (or steady-state growth rate) of well-being, although different clubs may exhibit different equilibria (Durlauf 1996, Galor 1996). Such characteristics could have geographic (Jalan \& Ravallion 2005, Sachs 2014) or institutional (Acemoglu, Johnson \& Robinson 2001) origins at macro scale, or arise from cognitive or physical limitations from birth (Almong \& Currie 2011), sociocultural identities (Fan and Loury 2005) or other immutable characteristics at micro or meso scales. Within an appropriately defined club, persistent poverty is the natural consequence of the group-defining characteristic, resulting in a single equilibrium poverty trap. In such cases, the feasible technologies are collectively insufficiently productive to generate a non-poor standard of living and whole subpopulations remain poor in expectation indefinitely in the absence of structural change to create a nonpoor equilibrium. Short of changing the underlying biophysical or socioeconomic environments that give rise to the unique, poor equilibrium, the only effective poverty reduction policy response to a single equilibrium poverty trap is a transfer program of indefinite term.

The dominant poverty trap models in the literature revolve, however, around multiple dynamic equilibria, meaning that both poor and non-poor equilibria exist. Multiple dynamic equilibria arise due to multiple market failures that induce the poor to choose behaviors that reinforce their initial poverty. The existence of multiple stable states implies the existence of thresholds (also called bifurcations, separatrices, tipping points, or unstable equilibria) at the boundaries of each stable dynamic equilibrium's basin of attraction.

Multiple equilibria poverty traps carry powerful policy implications (Barrett \& Carter 2013). First, small interventions can prove ineffective, only changing the short-term path to the same long-term state. Interventions must be substantial enough to shift a unit's well-being path dynamics, not just its current position on the pre-existing path dynamics to a poor 
equilibrium. Second, interventions that are substantial enough to move a unit onto a path toward a non-poor equilibrium can be of limited duration. Policy need only induce behaviors that endogenously carry people to a non-poor steady state once the intervention ends. Third, risk becomes especially important as shocks can exogenously knock a unit from one basin of attraction to another. Fourth, multiple equilibria imply that a certain amount of poverty is avoidable and unnecessary, which arguably makes intervention more ethically compelling.

A few figures may help sharpen the distinctions between single and multiple equilibrium poverty traps. Figure 1 displays a version of the canonical neoclassical model of economic growth, in which current well-being $\left(\mathrm{w}_{t}\right)$ maps to expected future well-being s periods ahead, $\mathrm{E}\left[\mathrm{w}_{\mathrm{t}+\mathrm{s}}\right]$, through a smooth concave growth function, $\mathrm{G}\left(\mathrm{w}_{\mathrm{t}}\right)$. The dynamic equilibrium - a point where expected future well-being equals current well-being, as represented by the intersection of the solid growth curve with the dashed diagonal locus of points reflecting values equal on both axes - occurs at $\mathrm{w}^{\mathrm{NP}}$, which lies strictly above the poverty line $\mathrm{p}$, noted by the red horiztonal and vertical lines. The clear implication is that initially poorer units grow faster than initially richer ones as all move towards a common steady-state level (or growth rate) of non-poor well-being, the well-known 'convergence' hypothesis. In such a world, poverty may exist but it is transient and no poverty traps exist.

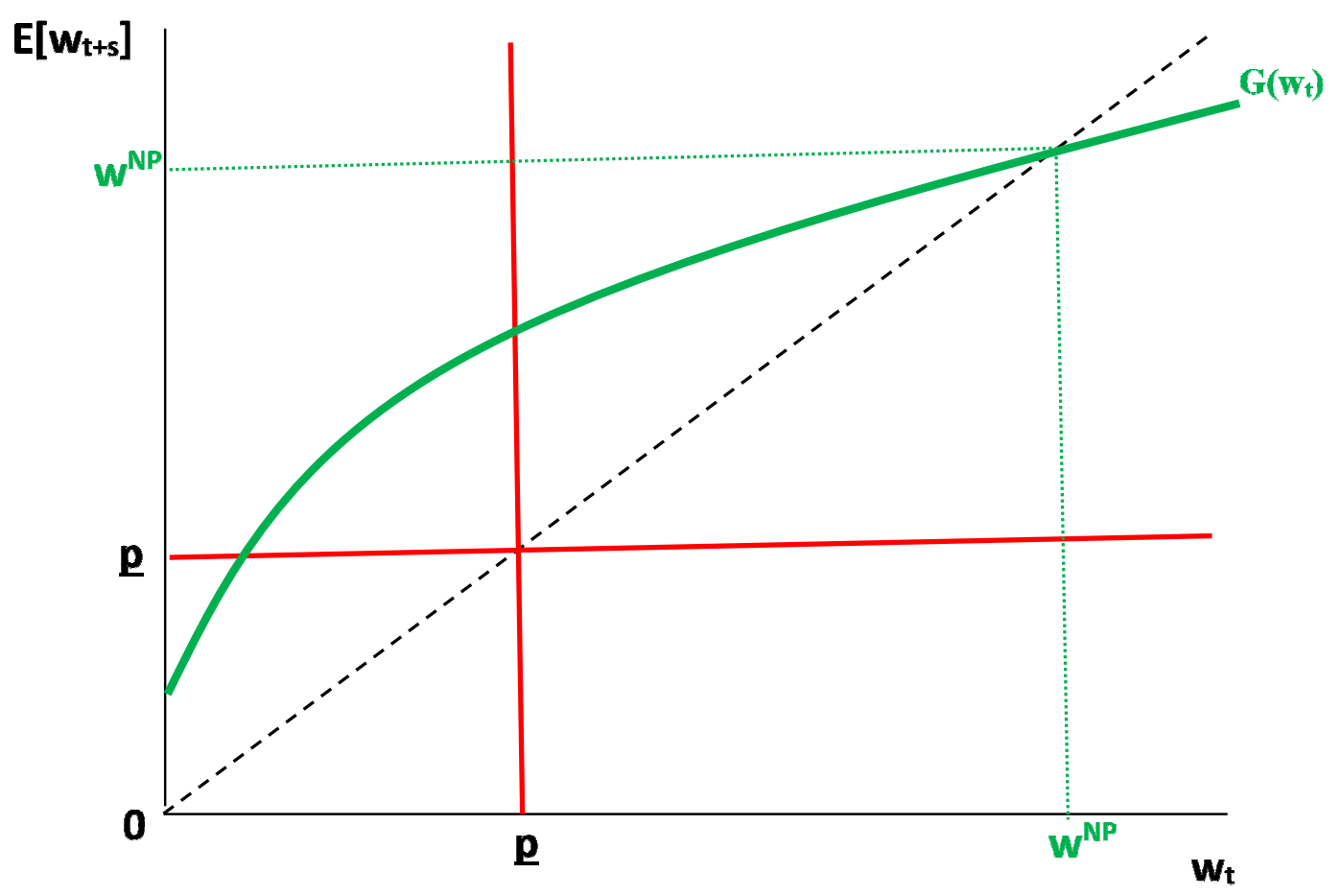

Figure 1: Well-being dynamics with no poverty trap

Figure 2 offers a simple refinement, adding a second, club-specific growth curve, $G^{*}\left(w_{t}\right)$, that leads to a dynamic equilibrium beneath the poverty line, $w^{\mathrm{P}}$. This represents the case of club convergence, with a single equilibrium poverty trap for those who belong to the group following the $G^{*}\left(w_{t}\right)$ path dynamics. Within each group, convergence holds, but for one subpopulation this leads only to a poor dynamic equilibrium in expectation. Absent 
interventions that enable movement from the dominated club to the dominant one, members of the former are trapped in persistent poverty indefinitely, albeit with the possibility of stochastic movements in and out of poverty due to random fluctuations around $G^{*}\left(w_{t}\right)$ that describes expected well-being dynamics for the poor group (Carter \& May 2001, Carter \& Barret 2006).

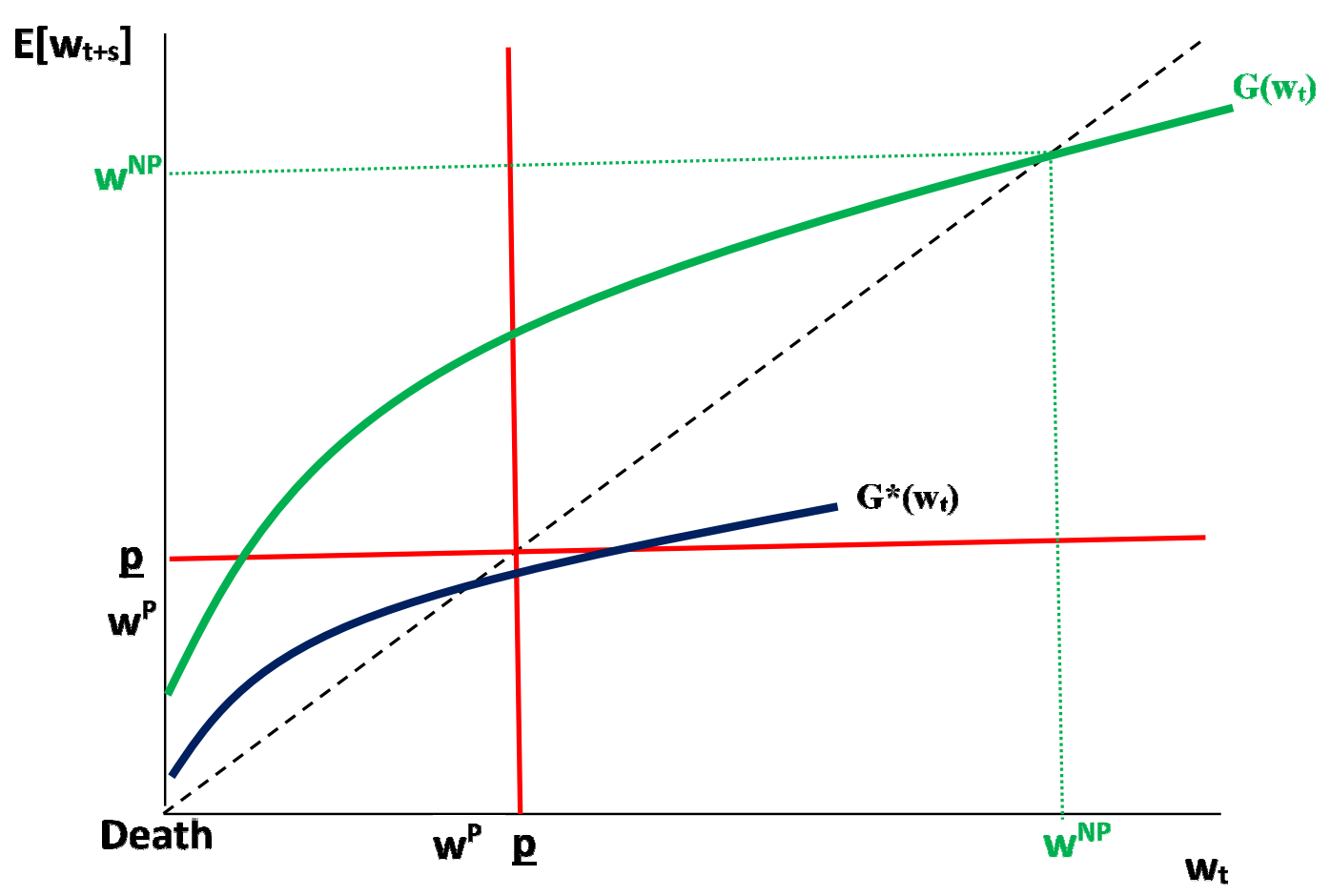

Figure 2: Well-being dynamics with a single equilibrium poverty trap for one subpopulation

Figure 3 depicts well-being dynamics with multiple equilibria for everyone in the population, adapted from Barrett \& Constas (2014). The non-concave growth function $\mathrm{G}^{\mathrm{M}}\left(\mathrm{w}_{\mathrm{t}}\right)$ generates three stable dynamic equilibria. The first is death at the minimum value of the range of feasible well-being; the second is a poor standard of living; the third is a non-poor standard of living. There exist some thresholds, T1 and T2, that separate the basins of attraction around each of the stable dynamic equilibria, leading to three distinct regimes: (i) a humanitarian emergency zone (HEZ, shaded in red) within which populations are collapsing toward death, (ii) a chronic poverty zone (CPZ, shaded in yellow) within which modest shocks - either positive or negative - do not alter the expected convergence toward a poor standard of living, and (iii) a non-poor zone (NPZ, shaded in green) within which people are expected to recover from non-catastrophic shocks. Anyone in either CPZ or HEZ is chronically poor in expectation.

We add conditional transition distribution functions - the vertical curves - to reflect the stochastic transitions from one period to the next due to asset and income risk, prospective illness, productivity shocks, non-equilibrium behavioral errors, etc. in such a way as to expressly accommodate possible conditional heteroskedasticity or skewness reflecting 
potentially heterogeneous risk exposure across the well-being distribution. Realizations beneath the lower (red) dashed horizontal line - reflecting T1, the unstable dynamic equilibrium that separates HEZ from CPZ - are expected to propel a person onto a dangerous slide toward death. At the most basic level, everyone faces a multiple equilibria poverty trap because death - whether due to predictable decline or a shock - is an absorbing state and, presumably, represents a poor standard of (non-)living. Conversely, a positive draw above the upper (green) dashed horizontal line - reflecting T2, the unstable dynamic equilibrium separating CPZ from NPZ - leads to escape from poverty in expectation. These stylized depictions reflect a critical feature of multiple equilibrium poverty traps: transitory shocks that do not change the basic parameters of the underlying well-being dynamics - e.g., from an iid $\mathrm{G}^{\mathrm{M}}\left(\mathrm{w}_{t}\right)$ process - can have permanent impacts by moving people into a different basin of attraction. In such a world, everyone faces some probability of falling into persistent poverty, but that probability varies markedly by initial condition and over time.

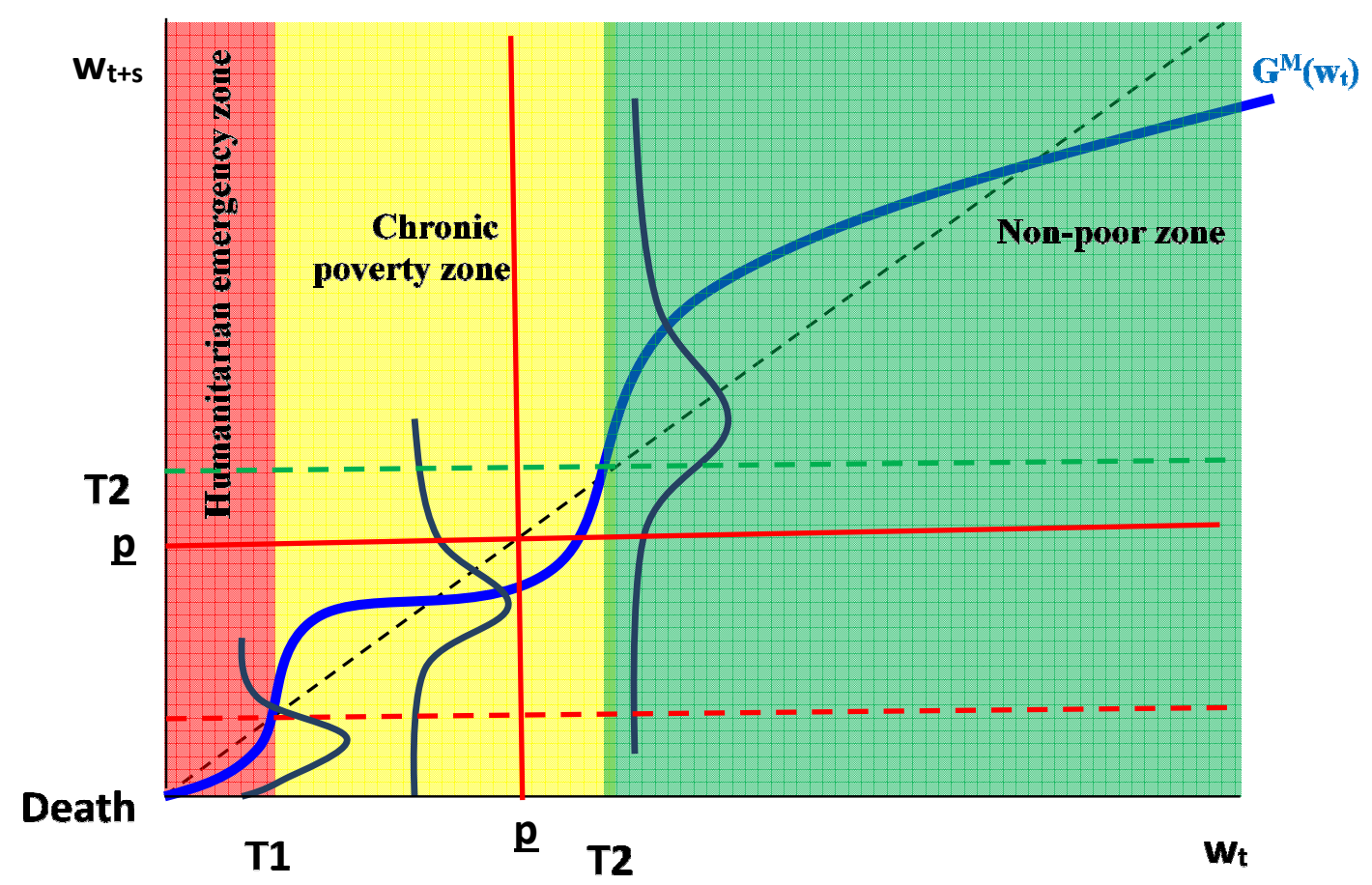

Figure 3: Multiple equilibrium well-being dynamics with conditional transition distributions

One challenge in empirical implementation of multiple equilibrium poverty trap models is that survivor bias will impede identification of dynamics in the HEZ. Outside of that zone, a multiple equilibria poverty trap such as that depicted in Figure 3 may exist among the subset of living dynamic equilibria in some places, a single equilibrium poverty trap of the sort shown in Figure 2 may exist for some populations, and there may be no poverty trap (Figure 1) for other sub-populations. The prospective within-population heterogeneity foreshadows 
one of the formidable challenges of estimation of poverty trap models, as we discuss in section 3. The remainder of this section focuses on a range of mechanisms that might result in multiple equilibria poverty traps.

\subsection{Multiple Technologies and Poverty Traps}

Multiple equilibria poverty traps arise in the presence of multiple technologies where some economic units lack access to more remunerative technologies because structural barriers prevent them from adopting such technologies. The most familiar examples concern impediments to uptake of improved agricultural technologies. For example, (Feder et al. 1985) show that binding credit constraints, uninsured risk exposure, exclusion from extension services, and so on discourage adoption of improved agricultural technologies. Other studies focus on how multiple market failures lead households to self-select out of more remunerative livelihood strategies (Barrett et al. 2001a, 2001b, 2006; Dercon 1998).

A variation on that theme concerns underinvestment in high-return assets. Whether studying investment in irrigation wells (Fafchamps \& Pender 2012) or in livestock (Rosenzweig \& Wolpin 1993), researchers routinely find that poor households systematically invest less in higher-return, higher-risk assets than better-off households do (Rosenzweig \& Binswanger 1993). This could arise due to decreasing absolute risk aversion, or to a positive correlation between (typically unobservable) ability or credit access and initial well-being, implying that the poor perceive lower risk-adjusted returns to investment than do the better-off.Similarly, a variety of financial, infrastructural, and institutional barriers generate non-random placement and selection into remunerative contract farming arrangements that commonly exclude initially poor growers (Barrett et al. 2012, Reardon et al. 2009) These and other examples illustrate how any of several market failures lead to inefficient investment, marketing, and production patterns, and that these effects are greatest amongst the poor. Moreover, failure to adopt improved technologies imposes a welfare cost not only on nonadopters but also on society as a whole if it affects aggregate supply and thus prices in general equilibrium. The macro-micro feedback between partial and general equilibrium can entrench low-level equilibria (Barrett \& Swallow 2006).

The common denominator to all such stories is the existence of a range of technologies that units can use to map asset holdings into income streams and the observation that many households seem to choose relatively low return options. Understanding what drives such choices is therefore a central question in research on well-being dynamics and poverty traps.

\subsection{Exclusionary Mechanisms}

Multiple equilibria poverty traps fundamentally require some exclusionary mechanism(s) that bar units from acquiring - by whatever means, whether borrowing, investment, etc. - the assets or technologies necessary to ensure endogenous convergence towards a non-poor steady state equilibrium over a reasonable time horizon. Multiple exclusionary mechanisms exist. In this sub-section we focus on financial and social exclusion before discussing mechanisms linked to human capital accumulation and natural capital feedbacks in the subsequent sub-section. 


\subsubsection{Financial Exclusion}

Perhaps the most common theoretical framework for understanding multiple equilibria poverty traps is the multiple financial market failures (MFMF) model (Galor \& Zeira 1993, Barrett et al. 2008, Besley 1995). The model has several key implications, as summarized by (Barrett \& Carter 2013). First, "endowments are expected fate" (p.981). Only for a narrow window of endowed abilities and initial assets, do multiple equilibria exist. For each ability level, there is a Micawber Threshold (MT), above which an individual converges to a nonpoor stable equilibrium and below which an individual falls into a poverty trap (Carter \& Barrett 2006, Zimmerman \& Carter 2003). Second, "risk matters and shocks have permanent consequences" (p.981). A household pushed below the MT by a shock can suddenly find itself converging on a low-level equilibrium from which it may not be able to recover; households attempt to manage risks so as to avoid such shocks. Third, single and multiple equilibria poverty traps can exist simultaneously as individuals with low abilities may face a unique, poor, equilibrium and those with high abilities may face a unique, non-poor, equilibrium, no matter their initial asset levels. Fourth, "systemic change matters" (p.981); i.e. changes in production and exchange technologies or in the natural, social, and/or market environment may change the dynamic equilibria of the system.

The MFMF model also has important implications regarding potentially observable behavioral responses to shocks and interventions (Barrett \& Carter 2013). Three merit special attention.

\section{(a) Asset smoothing}

The permanent income hypothesis assumes an exogenous, stationary income generating process in which savings to smooth consumption is the sole purpose of asset accumulation. In a more realistic model in which asset accumulation impacts future income, and in the presence of multiple dynamic equilibria, households just above the MT optimally may engage instead in asset smoothing behavior, preferring instead to destabilize consumption so as to protect productive asset holdings when faced with asset and income shocks (Carter \& Lybbert 2012, McPeak 2004, Zimmerman \& Carter 2003).

\section{(b) Distorted risk-taking behavior}

When individuals or households face multiple equilibria poverty traps, observed risk-taking behavior reflects not just static preferences but also forward looking risk management (Lybbert et al. 2013). As a result, those just below the poverty trap threshold may engage in (seemingly excessive) risk-taking behavior in the hope that a positive draw will move them above the threshold and onto a path towards a higher-level stable equilibrium. Conversely, those further below the MT and closer to a survival threshold may engage in (seemingly excessive) risk avoidance, choosing stable livelihoods offering incomes barely above subsistence minima while foregoing higher-return but risky investment opportunities (Barrett et al. 2006, Carter \& Barrett 2006).

(c) Investment and savings behaviors 
The MFMF model also implies that small asset transfers or safety net schemes can have outsized effects on investment and savings. If small transfers to individuals just below the MT push them above the MT, they can crowd-in additional savings or investment by making it feasible to reach a higher steady state capital stock. Absent transfers, such individuals would be unable to achieve the high-level steady state and therefore have no incentive to invest or save (Barrett \& Carter 2013). Similarly, by mitigating risk, asset insurance and safety net schemes can crowd-in investment, not only lowering the MT but also raising both the high and low level equilibria, and thereby reducing overall poverty (Barrett et al. 2008, Janzen et al. 2012).

\subsubsection{Social Exclusion}

When informal arrangements substitute for anonymous markets for finance, information, etc., economic units can find themselves trapped in poverty as a result of social exclusion or isolation. The propensity of people to associate mainly with similar others--e.g., the poor networking mainly with other poor people, and the rich with the rich-can generate multiple equilibria naturally from signaling, sharing or learning effects. A number of studies have built on earlier theoretical work (Calvo-Armengol \& Jackson 2015, Montgomery 1991) to demonstrate the role of social networks in perpetuating or combating poverty (Chantarat \& Barrett 2011, Conley \& Udry 2010).

Social exclusion may induce poverty traps in three distinct ways. First, when individuals need social networks to overcome the fixed costs related to information or adoption of improved technologies, associational propensities can generate multiple equilibria depending on the broader distribution of wealth in society (Chantarat \& Barrett 2011, Mogues \& Carter 2005, Moser \& Barrett 2006). Second, social networks also provide learning in labor markets as well as signaling (positive and negative) that can have strong influence on labor market outcomes (Calvo-Armengol \& Jackson 2015, Beaman \& Magruder 2012), Montgomery 1991). Where information is not uniformly available and often asymmetric, networks can confer significant advantages on well-connected members. Relatedly, group-wise discrimination can serve a similar function, wherein signals of (non-) membership in a distinct social group affects employment opportunities (Bertrand \& Mullainathan 2004). Third, social networks play a key role in migration that can enable escape from geographic poverty traps by reducing the costs of migration, increasing the density of options available to prospective migrants, or both (Chay \& Munshi 2011, Munshi 2011, Bazzi 2015) ${ }^{1}$.

\subsection{Non-financial Capital Accumulation}

Besides financial or social exclusionary mechanisms that fall firmly within the social science literature, there also exist biophysical mechanisms that can give rise to multiple equilibria poverty traps and commonly cross disciplinary boundaries into the natural sciences. Especially for the rural poor, for whom human and natural capital form the basis for most livelihood options, well-being dynamics depend fundamentally on the biophysical

\footnotetext{
${ }^{1}$ More recent evidence suggests that there can also be a cost to social inclusion. The same networks that can support migration can also inhibit migration by inculcating identity that, while initially useful in informal insurance and contract enforcement, can restrict the ability of members to leave the network (Munshi \& Rosenzweig, 2015).
} 
mechanisms that underpin the dynamics of human health and nutrition as well as of fish, forests, land, water, and wildlife.

\subsubsection{Human Capital}

Historically, human capital accumulation has been the primary channel through which people escape poverty (Deaton 2013, Fogel 2004). But poverty can also perpetuate conditions that impede human capital accumulation. When such a situation prevails, and particularly when the effects of low human capital are irreversible, a poverty trap exists. Shocks to and degradation of human capital acquisition can occur during childhood or throughout adulthood; we discuss each in turn.

\section{Early childhood nutrition, health and education}

The public health literature has long hypothesized that maternal disadvantage in-utero and neo-natal shocks can have large and sustained effects on the brain and other organs' development and consequently on long-term human capital accumulation (Aizer \& Currie 2014, Almond 2011). The irreversibility of early childhood cognitive and physical development failures makes an especially compelling case for a poverty trap mechanism if such failures are systematically related to the well-being of the households in which children are born and raised (Loury 1981). The various mechanisms that impede human capital accumulation early in childhood, by those too young to choose their investment behaviors, helps explain high observed rates of intergenerational transmission of poverty and low educational and health status (Bhalotra \& Rawlings 2013).

One line of this research focuses on cumulative disadvantage and the intergenerational transmission of various well-being indicators (income, health, education, etc.). A vast literature clearly establishes that poor mothers typically give birth to smaller, less healthy, infants who have poorer adult education and health outcomes than do healthier newborns (Bhutta et al. 2013, Victora et al. 2008). A key finding of that literature is that active intervention to counter maternal disadvantage early in life can help reduce the intergenerational transmission of poverty (Aizer \& Currie 2014).

A second documents how a range of in-utero and early childhood shocks appears to lead to adverse child and later life outcomes. A large number of studies find that climatic, conflict or environmental shocks during infancy or in-utero have adverse long-term outcomes on adult educational attainment and health (Almond et al. 2009, Bharadwaj et al. 2015, Maccini \& Yang 2008). In so far as poor children are disproportionately exposed to such risks, their poverty impedes human capital accumulation stochastically.

A third focuses on how parents facing MFMF often cannot borrow to make human capital investments in their children, so that in the absence of resource pooling to finance early childhood interventions, the children of poor parents are likely to become poor adults (Loury 1981). Because early childhood family environments are major predictors of children's accumulation of cognitive and non-cognitive skills, environments that fail to cultivate these skills leave children worse off, with lifelong behavioral and well-being consequences (Conti et al. 2010, Heckman 2006). 


\section{Adult buman capital}

One of the best developed multiple equilibria poverty trap theories turns on the idea that physical work capacity declines more rapidly than wages once wages, and the food they can buy, fall below a critical level (Dasgupta \& Ray 1986, 1987; Dasgupta 1993, 1997; Ray \& Streufert 1993, Stiglitz 1976, Bliss \& Stern 1978). In the simplest version of this theory, in equilibrium, a subset of workers obtain employment and enjoy a higher standard of living than the unlucky who are rationed out of the labor market due to a nutritional "efficiency wage" below which it is suboptimal to employ workers because the wage is insufficient to sustain their labor power. ${ }^{2}$ In poor economies, the marginal revenue product of labor may be less than this minimum wage rate, leading to involuntary unemployment. In the absence of credit or insurance, consumption then tracks income; consequently, the poor lose physical work capacity and, thereby, productivity, making it harder still to secure employment and reinforcing the condition (Schofield, 2014).

Other intuitive shocks to adult human capital include death and disease, either of which reduces household labor supply and thus earnings capacity. Because spending on disease prevention and treatment naturally increases with income and affects the future stocks of pathogens, disease-based poverty traps are a natural outgrowth of coupled biophysical and socioeconomic processes (Bonds et al. 2010, Ngonghala et al. 2014).

A very different mechanism receiving growing attention in the literature deals with behavioral patterns that reinforce poverty. Two key channels are at play here. First, individuals could face exogenous, immutable self-control problems or addictions that can result in a single equilibrium poverty trap (Schilbach, 2015). However, as Barrett \& Carter (2013) note, multiple equilibria can emerge if the behavior can be changed through "nudges" (Banerjee \& Mullainathan 2010, Thaler \& Sunstein 2009).

Second, poverty-reinforcing behaviors could emerge endogenously due to stress and induced change in preferences (Haushofer \& Fehr 2014). One such mechanism posits that the psychological stress of poverty endogenously reduces cognitive capacity, leading to reduced productivity, and thereby a poverty trap (Mani et al. 2013, Shah et al. 2012, 2015). A different mechanism arises from preferences that evolve endogenously in response to material conditions associated with persistent poverty. Poor individuals' time horizons, and thus their discounting of future gains from current investments, may vary directly with their perception of their future prospects, with poorer people exhibiting shorter planning horizons (Laajaj 2015). Exposure to violence or other traumas more common in poor areas may increase risk aversion, resulting in a lower standard of living (Moya 2012).

\subsubsection{Natural Capital and Ecological Feedback Effects}

Poor communities, particularly in rural areas, often rely on natural capital as productive assets. Poverty traps may form and persist through feedbacks with natural resources, although the literature on such mechanisms remains strikingly thin. Barrett \& Arcese (1998)

\footnotetext{
${ }^{2}$ In more complex versions of the nutritional efficiency wage literature, job rationing is correlated with asset ownership, with the best-endowed potential workers hired first, leading to a critical asset threshold that separates the non-poor from those mired in poverty and malnutrition.
} 
model the coupled dynamics of wildlife population and human consumption and poaching behavior in an environment of imperfect labor and product markets, and static agricultural technology subject to environmental shocks. Such models naturally permit exploration of how market failures condition the dynamics of any natural resource on which communities rely, such as fisheries, water resources, forests, or shared grazing lands. These are variations on the classic problem of the commons in which communities, as a result of coordination failures, overexploit natural resources, degrading the resource below a recoverable threshold and compromising communities' future livelihoods (Baland \& Platteau 1996, Hardin 1968, Ostrom 1990). Such depletion of community assets can lead to a poverty trap (Toth 2014).

However, coordination failures are not the only mechanism through which natural capital affects the dynamics of poverty. Increasingly, the public health literature has emphasized 'one-health', the notion that the health of ecosystems and of the communities that occupy them are inherently connected (Keesing et al. 2010). Garg (2015), for example, finds that loss of forest cover in Indonesia substantially increases the levels of malarial infection in communities near the forest through a purely ecological channel. Such disease incidence can generate poverty traps through channels discussed above. Yet, Foster \& Rosenzweig (2003) find that at least in the case of forests, local economic growth can stimulate demand for ecological services suggesting that positive shocks that result in local economic activity have the potential to avoid or overcome ecological poverty traps. Relatedly, Tittonell \& Giller (2013) and Barrett \& Bevis (2015) report on multiple mechanisms by which soil quality degradation and mineral depletion can have long term productivity impacts, both by endogenously discouraging uptake of more productive technologies (e.g., inorganic fertilizers) and by fostering micronutrient deficiencies within semi-subsistence farming households.

\section{Estimation methods and empirical evidence}

Having briefly reviewed the range of mechanisms posited to give rise to poverty traps in the conceptual literature, we now consider the empirical evidence on well-being dynamics and poverty traps, beginning with the methodologies and associated methodological challenges of observing these dynamics in data. Kraay \& McKenzie (2014) review the literature on country level, big-push/coordination failure, hunger/nutrition-based, and entrepreneurial (i.e. borrowing constraints combined with non-convex production technologies) poverty traps and conclude that poverty traps "are rare and largely limited to remote or otherwise disadvantaged areas" (p.129). Their review, while overlooking some important mechanisms and studies, provides a valuable reminder that not all persistent poverty signals a poverty trap. Yet it seems almost tautological that readily identifiable poverty traps are most strongly associated with 'disadvantaged areas', where simpler theory and standard policy prescriptions have proved less effective. Furthermore, there are several reasons why one might fail to empirically observe a poverty trap where it does exist, as we explain below, so that the absence of evidence is not evidence of absence. For example, the finding that nationally representative household data do not exhibit distinct multiple equilibria is entirely consistent with any of several data generating processes, including not only one with no poverty trap, but also ones in which the full population represents a mixture distribution with at least one subpopulation facing a poverty trap mechanism that is difficult to identify without properly identifying the structural characteristics that generate club-specific well-being dynamics. 
Careful empirical work on poverty traps requires contextually-appropriate theory that informs testing in accord with relevant hypothesized mechanisms.

After thorough review of the empirical evidence for single and multiple equilibria poverty traps, we conclude that, although the empirical findings may be sensitive to choice of data, estimation technique, and the well-being indicator examined (e.g., income, consumption, an asset index), the available evidence generally supports the theory of poverty traps. However, the empirical evidence supporting particular types of poverty perpetuating mechanisms is more mixed. Much work remains to be done to identify specific mechanisms at play among distinct subpopulations in order to inform policy and interventions aimed at liberating the poor from the hopelessness that too often accompanies persistent poverty.

\subsection{Methodologies for identifying poverty traps}

As discussed in the previous section, poverty traps may arise through a variety of mechanisms. A number of tools have been developed to identify these mechanisms and their signatures, both directly and indirectly.

\subsubsection{Direct methods of testing for poverty traps}

Direct methods entail observing either the asset dynamics or the mechanisms that generate them. In reviewing methods to describe well-being dynamics, Carter \& Barrett (2006) delineate four generations of poverty assessment as they have progressed in the literature. The first generation approach identifies the poor from the non-poor using static income or expenditures; the second identifies the transitorily poor from the chronically poor using income or expenditure dynamics; the third further breaks the category of chronic (or transitory) poverty into subcategories of structural or stochastic chronic (or transitory) poverty using a static asset poverty line; the fourth generation poverty assessment approach separates households into the persistently poor and the dynamically mobile using asset dynamics. Other direct approaches to observing poverty traps include eliciting statedependent wealth or well-being dynamics using games or experiments (Santos \& Barrett 2006) or using threshold estimation techniques (Carter et al. 2007, Hansen 2000).

It may nonetheless be difficult to observe bifurcating asset dynamics and associated equilibria or thresholds directly, for several reasons (Barrett 2005, Barrett \& Carter 2013). First, empirical identification of multiple equilibria is difficult due to unobserved heterogeneity and general equilibrium effects. Studying dynamics requires longitudinal observations of the same economic units (i.e., panel data) and a strong assumption that the underlying data generating process remain unchanged over time and is shared among all units in the sample. Yet, the few studies that attempt estimation of group-specific dynamics commonly find heterogeneity (Carter \& Lybbert 2012, Santos \& Barrett 2006). Relatedly, it can be difficult to empirically discern between coinciding single equilibria wherein low-ability individuals face a single low-level equilibrium and those with high abilities face a single highlevel equilibrium, and a true dynamic multiple equilibria (Santos \& Barrett 2006). Likewise, it can be difficult to discern heterogeneity from state dependence.

Furthermore, changes in the social, economic, and/or natural environment - some of them 
induced by the dynamics under study - should, in principle, change the underlying behaviors and consequently change the equilibria. The parameters describing well-being dynamics are therefore endogenous, making direct estimation of such dynamics fraught.

Second, data constraints impose serious limitations on econometric estimation. Where multiple equilibria exist, the estimable thresholds should be dynamically unstable, so one should find a limited number of observations around these thresholds in any sample (Barrett 2005, Barrett \& Carter 2013, Naschold 2013). In addition, those sub-samples found near the dynamically unstable equilibria are necessarily non-random (Barrett 2005, Barrett \& Carter 2013). The spell length (time) between panel observations may also have serious impacts on assessment of well-being dynamics. Naschold \& Barrett (2011) find that shorter spell length is correlated with findings of spurious-because stochastic-income mobility that is canceled out in longer spells.

Third, the choice of well-being indicator can significantly affect the dynamics one observes. Michelson et al. (2013) show that the empirical tests for poverty traps defined in relation to an asset index are not robust to the methodology used to generate that asset index. In particular, they find that structural income asset indices are more likely to find poverty traps than are other types of indices. Likewise, Barrett et al. (2006) show different outcomes using structural income (income data stripped of measurement error and stochasticity) than using total income across two case study countries. Whereas total income dynamics show no evidence of poverty traps, the structural income dynamics are consistent with the theory of poverty traps.

Fourth, estimation techniques may play an important role in whether one observes a poverty trap or not. Parametric and non-parametric approaches to econometric estimation of assetdynamics each have their strengths and weaknesses. Parametric methods are useful as they allow the econometrician to control for household characteristics and a variety of assets. And parametric methods with high-order polynomials can allow for enough flexibility to observe non-linear welfare dynamics. However, to estimate welfare dynamics using highorder polynomials, one needs large amounts of data both in the cross-section and time series dimensions. Even with generous amounts of data, the effects in which one is interested may be hidden in heteroskedastic and positively autocorrelated errors (Barrett 2005).

Nonparametric methods allow one to estimate more flexible dynamics. However, nonparametric approaches come with their own challenges. In order to avoid the curse of dimensionality, one must either limit the analysis to a few, or a single, asset(s) or aggregate the variables of interest into an asset index. Single asset poverty traps have been observed by Barrett et al. (2006), Lybbert et al. (2004), Santos \& Barrett (2011) and others among rural herders in Kenya and Ethiopia. In more complex economies, however, poverty traps may be driven by a variety of assets that may also have differential effects depending on household and/or location characteristics for which one cannot easily account in a nonparametric setting (Adato et al. 2006). The common practice of collapsing a set of assets into a single index for the purpose of non-parametric estimation also has potential pitfalls (Michelson et al. 2013). One alternative non-parametric approach involves using machine learning methods such as classification and regression trees (Breiman 2001, Loh 2002), which recursively 
partition the data into ever more homogenous groups; such approaches are used by Durlauf \& Johnson (1995), Tan (2010), and Santos \& Barrett (2006).

Semi-parametric methods can allow for flexible form estimation while not sacrificing control variables; however, very few analyses employ this method. Naschold (2013) determines that parametric, non-parametric, and semi-parametric estimators perform about the same in identifying single equilibrium poverty traps in data from Pakistan and Ethiopia.

Finally, Barrett \& Carter (2013) note that failure to empirically identify a poverty trap may result from the misinterpretation of evidence against multiple equilibria poverty traps as evidence against the existence of any poverty trap, including of the single equilibrium variety, for which there exists considerable empirical evidence (Giesbert \& Schindler 2012, Jalan \& Ravallion 2002, Kwak \& Smith 2013, Naschold 2012, 2013; Quisumbing \& Baulch 2013).

\subsubsection{Indirect methods of testing for poverty traps}

Indirect methods entail observing behaviors consistent with poverty trap theory that should not otherwise be observed. As discussed in section 2.2.1, the MFMF theory of poverty traps suggests several behavioral responses that have empirically testable hypotheses. Several recent papers have taken this indirect route to testing for poverty traps.

Drawing on Zimmerman \& Carter (2003) and McPeak (2004), Carter \& Lybbert (2012) note that "the marginal value of assets will become extraordinarily high in the neighborhood of critical wealth levels; households in these neighborhoods will be reluctant to liquidate assets even in the face of economic shocks;" rather, these households will smooth assets as an equilibrium strategy. They therefore test and find support for the hypothesis of two behavioral regimes observed in response to a shock and in the neighborhood of a threshold: asset smoothing and consumption smoothing. Hoddinott (2006) similarly finds markedly different livestock sales behavior in response to shocks above and below a natural herd size threshold in rural Zimbabwe.

Various papers have noted that poorer risk-averse households faced with high-income volatility should will be willing to exchange expected income growth for lower income volatility (Carter 2010, Rosenzweig \& Binswanger 1993). Combining this hypothesis with the asset smoothing hypothesis suggests that consumption smoothing increases in expected income. Barrett et al. (2006) test the dual hypotheses of "wealth differentiated portfolio choice" and asset smoothing via comparison of the coefficient of variations of income and consumption. An additional behavioral implication of income and asset smoothing among those within a poverty trap is lower expected marginal returns on assets. Barrett et al. (2006) show that this hypothesis is easily tested via a non-parametric regression of income on assets.

Poverty trap theory indicates that risk is especially costly for asset smoothers (Carter \& Lybbert 2012), suggesting that insurance and credit interventions can be used indirectly to identify behaviors and well-being dynamics consistent with poverty traps (Janzen et al. 2012, Chantarat et al. 2015). Thresholds associated with multiple equilibria should also generate a focal point around which informal credit should concentrate and should lead to social exclusion of those structurally unlikely to be able to maintain mutual lending and insurance 
commitments, as Santos \& Barrett (2011) find among southern Ethiopian pastoralists.

\subsection{Empirical evidence on poverty traps}

Through both direct and indirect estimation methods, and despite the many challenges inherent to both lines of inquiry, both single and multiple equilibria poverty traps have been empirically observed at both the macro and micro level. The following subsections summarize the evidence, beginning with single equilibrium poverty traps before moving to multiple equilibria poverty traps.

\subsubsection{Evidence of single equilibrium poverty traps}

A considerable literature has explored different implications of the poverty traps hypothesis at the macro-level, using country-level data. While in this paper we focus mainly on microlevel studies, a brief summary of the macro literature is useful to highlight a few key empirical regularities. Chief amongst these is the existence of distinct economic growth regimes based on countries' initial conditions (Azariadis \& Stachurski 2005, Durlauf \& Johnson 1995, Quah 1993, Tan 2010). There seem to be two broad explanations for such hysteresis: institutions and geography. The institutional explanations have garnered considerable attention in recent years, focusing on phenomena such as ethnic fractionalization, weak property rights, public goods provision, and other institutions thought essential to promoting investment and development (Acemoglu et al. 2001, Banerjee \& Iyer 2005, Dell 2010, Easterly \& Levine 1997, Iyer 2010, Nunn 2007, 2009; Tan 2010). The macro literature on geographic poverty traps has focused primarily on how countries' disease burden, agricultural growing conditions, and distance from sea ports condition their growth experience, suggesting that these physical geographic features naturally attenuate investment incentives and growth prospects (Bloom et al. 1998, Gallup et al. 1999).

The institutions literature has largely not moved down to microeconomic levels of empirical analysis for the simple reason that most institutions cut across large populations, making it difficult to find adequate within-sample variation with which to identify causal effects of institutions on well-being dynamics. Green (2011) and Green \& Moser (2013) are noteworthy exceptions, exploiting local-level variation in institutional indicators to identify associations with investment and well-being dynamics.

The geographic poverty traps literature, by contrast, has permeated the microlevel empirical literature. Most notably, Jalan \& Ravallion (2002) define geographic poverty traps as a situation wherein "characteristics of a household's area of residence-its 'geographic capital' - entail that the household's consumption cannot rise over time, while an otherwise identical household living in a better-endowed area enjoys a rising standard of living." They find evidence of a single equilibrium geographic poverty trap in southern rural China in the late 1980s. In particular, areas that are mountainous, with lower initial health indicators (i.e., infant mortality rate and medical personnel per capita), and less road infrastructure experience lower consumption growth rates. Barrett et al. (2006) similarly find marked differences in household-level well-being dynamics across different geographies within Kenya and Madagascar, consistent with the notion of geographic poverty traps. Krishna et al. (2006) and Whitehead (2006) also find support for the geographic poverty traps hypothesis 
in their studies of Uganda and Ghana, respectively.

A number of studies exploring welfare dynamics at the micro level search for multiple equilibria but find single equilibrium poverty traps. Kwak \& Smith (2013) find a shift from a single equilibrium in the late 1990s to a bimodal asset distribution suggestive of emerging multiple equilibria in the early 2000s in an Ethiopian panel dataset. When all periods are analyzed together, the authors find a single low level asset equilibrium at or below the poverty line. Kwak \& Smith (2013) also apply Jalan \& Ravallion (2002) test for geographic poverty traps across the data and find that one of the three agro-ecological regions under study, the enset growing region, is indeed facing a very low long run expected equilibrium.

Giesbert \& Schindler (2012) explore household welfare dynamics in rural Mozambique using a two wave panel dataset from 2002-2005. Employing a variety of estimation techniques and asset indices, they find that all households are expected to converge to a single low welfare equilibrium in the medium term, which the authors interpret as a sectoral-rural farm based economy-poverty trap. They also find evidence of conditional convergence wherein households of immigrants and well-educated heads achieve a higher equilibrium than do households without these characteristics. They find that drought, and the coping strategies deployed in response, are responsible for the observed welfare dynamics during the period under study. Similarly Naschold (2012) finds a single asset poverty trap in rural India with greater non-poor probabilities for those households with greater landholdings, more education, or those households belonging to higher castes.

Using both parametric and non-parametric methods, Quisumbing \& Baulch (2013) likewise find evidence of a single low-level equilibrium in analyzing asset dynamics in data from rural Bangladesh. Naschold (2013) similarly identifies single equilibrium poverty traps in Pakistan and Ethiopia using a variety of parametric, non-parametric, and semi-parametric estimators. These welfare dynamic results are robust to a number of sensitivity tests including various asset indexes and different panel data spell lengths.

\subsubsection{Evidence of multiple equilibria poverty traps}

While most evidence for multiple equilibria poverty traps are from meso and micro level studies, multiple equilibria welfare dynamics have been observed at the macro level as well. Bloom et al. (2003) find multiple equilibria in a cross-country analysis of 152 countries. Among low-level equilibrium countries, they find that geography and climate are significant determinants of GDP per capita. That is, there is a range of better and worse off countries within the poverty trap; the worse off countries are hot, landlocked, and have low seasonal rainfall. While they find that geography plays a role in the growth of the low-income countries, Bloom et al. (2003) reject an argument of simple geographic determinism. A more complex suite of factors appears to give rise to the multiple equilibria they identify.

At the microeconomic level of analysis, and supporting the idea that initial conditions play a role in perpetuating poverty, Adato et al. (2006) identify bifurcated asset dynamics in postapartheid South Africa consistent with a poverty trap story. Using nonparametric methods to observe the highly non-linear relationship between 1993 and 1998 asset indices, they find that those households with an asset level that is approximately twice the poverty line- the 
MT-will acquire assets over time while those beginning with an asset level below this threshold will collapse to the low-level poverty trap/equilibrium where the expected standard of living is 90 percent the poverty line.

Thomas \& Gaspart (2015) estimate a number of parametric models using household panel data from rural Madagascar covering the period 1996-2006. They likewise find considerable state dependence, wherein a range of characteristics associated with initially poor households - meager asset endowments, high dependency ratios, etc. - interact to generate a high degree of persistence in poverty.

A number of studies observe asset dynamics over a single, but extremely important, asset livestock - among pastoralists in east Africa and consistently find evidence supporting the hypothesis of multiple herd size, and thus human well-being, equilibria. Lybbert et al. (2004) find two stable dynamic livestock equilibria in southern Ethiopia-the lower equilibria at a herd size of one; the upper at a herd size of 40-75 cattle-and one unstable dynamic equilibrium, the MT, at 10-15 cattle. Barrett et al (2006) find remarkably similar equilibria among pastoralists in northern Kenya. In search of the causal mechanisms of the herd dynamics observed in Lybbert et al. (2004), Santos \& Barrett (2006) identify herder ability and livestock threshold levels that separate those rural pastoralists who increase their herd size over time from those who do not. The population as a whole appears a mixture of individuals facing single equilibrium poverty traps - those herders with poor animal husbandry skills - and others facing multiple equilibria arising from weather shocks that put a premium on skill in managing herds in times of stress.

Asset smoothing behavior, consistent with the theory of poverty traps, has been observed in numerous studies using indirect (sometimes coupled with direct) methods of assessing welfare dynamics. Using both structural income and an asset index to observe welfare dynamics, Barrett et al. (2006) find evidence of poverty traps in rural Kenya and Madagascar. Directly, they find that structural income and asset dynamics reveal multiple dynamic equilibria. Indirectly, they find evidence of asset and income smoothing as well as lower marginal returns to assets among the poorer households in Kenya.

Observing households' coping strategies and welfare dynamics following a shock provides additional insight into the relationship between shocks and poverty traps. Carter et al. (2007) undertake two case studies in which they find evidence that households can be pushed into poverty traps following natural disasters from which, by definition of a poverty trap, they are unable to recover without assistance. Assessing the effects of 1998 Hurricane Mitch on household asset dynamics in Honduras using Hansen's (2000) threshold estimation technique, Carter et al. (2007) find that households left with an asset level of $\$ 250$ or less after the hurricane will decline to a lower welfare equilibrium. The authors also assess the effect of a three-year drought in Ethiopia in the late 1990s on livestock assets. They find an asset threshold of 0.6 tropical livestock units, below which asset accumulation slows and eventually stops; they also find a pattern of asset smoothing among the poorest households. Likewise, using household panel data from Burkina Faso, Carter \& Lybbert (2012) find multiple smoothing regimes consistent with the behavioral implications of poverty trap theory. When confronted with an exogenous weather shock, Burkinabe households above the critical asset level where asset accumulation dynamics bifurcate optimally smooth 
consumption while those households below the critical asset level optimally smooth assets. Janzen and Carter (2013) similarly find that households' behavior bifurcates based on households' initial wealth in response to insurance against drought in northern Kenya.

Hoddinott (2006) also finds evidence of asset smoothing in the years following a drought in rural Zimbabwe using annual data from the mid to late 1990s. In particular, he finds that households with two or fewer cattle or oxen were much less likely to sell their livestock during the drought, suggesting that a threshold lies in this realm. Further investigating the effects of asset smoothing within households, Hoddinott (2006) finds that women's body mass index and the growth rates of children under the age of two fell as the household disrupted consumption to smooth assets while neither children over the age of two nor adult men were affected. Tragically, the undernourishment of the under two children is likely to lead to poorer productivity and lifetime earnings for these individuals in adulthood (Hoddinott 2006). In other words, the households avoided an immediate poverty trap based on household productive asset holdings by increasing the long run probability of a human capital-driven poverty trap.

In addition to unambiguous evidence that initial conditions matter to ensuing poverty dynamics and in favor of asset and income smoothing hypotheses most easily explained by the existence of multiple equilibria poverty traps, the literature also offers suggestive empirical evidence on the social capital, non-convex production technologies, multiple financial market failure (credit, insurance, etc), and biophysical/natural capital mechanisms.

Empirical evidence on the social exclusion poverty trap mechanism is quite limited and the results to date are mixed. Adato et al (2006) find, qualitatively, that social networks in postapartheid South Africa are helpful in so far as assisting households to cope with shocks or to look for work, but that they are not "connections that provide pathways out of poverty" (p. 244) due to pervasive poverty among the poor and high inequality within the society. Munshi (2011) presents evidence that new social networks can assist a person in escaping an occupational trap in India, a highly (vertically) segregated society.

Mogues \& Carter (2005) demonstrate that social capital, instead of alleviating the challenges of missing financial markets, can exacerbate inequalities through social exclusion and that such exclusion can result in remarkably different economic outcomes. Vanderpuye-Orgle \& Barrett (2009) likewise find that risk pooling fails for socially invisible (not well connected) individuals in Ghana. Santos \& Barrett (2011) show that households deemed to have experienced a shock that leaves them unlikely to be able to repay get endogenously rationed out of social lending arrangements.

The multiple financial market failure and non-convex production technologies mechanisms are very difficult to observe empirically due to data constraints. However, two studies have forayed into empirical analyses of these mechanisms. Examining microenterprises in Mexico, McKenzie \& Woodruff (2006) find no evidence of non-convex production technologies among firms with low levels of capital investment and therefore no barriers to entry due to low marginal returns at low levels of investment. They do find evidence of credit constraints, but note that these are not sufficient conditions for a poverty traps. Moser \& Barrett (2006) find low take up of SRI technology among poor Malagasy farmers due to seasonal family 
labor and liquidity constraints. As with McKenzie \& Woodruff (2006), while these constraints can serve to perpetuate poverty, they are not sufficient evidence of a poverty trap.

In an experimental setup well-designed to assess the risk mechanism, Bryan et al. (2014) randomly incentivize internal seasonal migration in Bangladesh and find that the returns are large. However, they also find that many who would benefit from migration, but are too close to a subsistence level of welfare, do not undertake the savings necessary to finance the migration due to the risk that migration will not yield expected benefits. They argue that these findings are consistent with a poverty trap model in which very poor households avoid the risky investment of internal migration and therefore have structurally different (lower) consumption dynamics than those who can/do make the investment. They provide simulations demonstrating that those who fall below the consumption/cash-on-hand threshold necessary for migration never take the risk and remain in poverty, while those above the threshold enjoy the returns of the migration in more consumption/cash-on-hand.

Biophysical mechanisms have also been shown to produce poverty traps. In fact, natural systems related to soils and climate have been found to exhibit multiple equilibria and affect the asset dynamics of those whose livelihoods depend on these systems.

A range of bioeconomic models consistently find multiple equilibria related to farm size and soil quality. Antle et al. (2006) find multiple equilibria of high and low soil degradation status as well as a productivity threshold lying between them. They demonstrate that once the soil quality of a parcel of land has fallen below this productivity threshold, efforts to improve the soil quality become economically irrational. Stephens et al. (2012) use a bioeconomic model of agroecosystems, calibrated to data from rural Kenya, to explore how variation in households' land and livestock endowments affects livelihood portfolios and land management practices. They find that larger and higher quality land endowments permit accumulation of cash and livestock and conservation of soil organic matter relative to smaller farms or those with more degraded soils. They identify thresholds in land and livestock space that separate those who are able to maintain a productive asset portfolio and persistently avoid poverty from those who slide into or cannot escape from persistent poverty. Their results are strikingly similar to those generated by an earlier simulation model that similarly found bifurcated soil quality and farm earnings dynamics based on initial land conditions (Shepherd \& Soule 1998). Similar differentiated patterns of investment in soil conservation appear among farmers in the Philippines (Shively et al. 2001). Marenya \& Barrett $(2009 \mathrm{a}, \mathrm{b})$ further explore the soil degradation poverty trap mechanism finding that, below a threshold soil carbon level, fertilizer application yields low returns, making fertilizer investment economically unprofitable; therefore, Kenyan households' fertilizer purchase and application decisions are consistent with the multiple equilibria hypothesis.

Barrett \& Santos (2014) project observed livestock asset dynamics among Ethiopian pastoralists forward under various climate change scenarios to simulate the effects of increased or decreased drought on those dynamics. They find that doubling the frequency of drought relative to that presently observed would send the entire pastoralist system into a poverty trap, leading all households towards holdings of a single animal in a unique low level stable equilibrium. In the case of significantly decreased drought frequency, the poverty trap would disappear and expected herd size would grow, possibly exhausting rangeland 
resources in a tragedy of the commons scenario.

Widespread direct and indirect empirical evidence of poverty traps notwithstanding, it should be noted that several careful analyses of welfare dynamics find no evidence of either multiple or single equilibrium poverty traps. Antman \& McKenzie (2007), using a pseudopanel of income data from urban Mexico and allowing for individual heterogeneity, find no evidence of a poverty trap. In a parametric analysis using income data, Lokshin \& Ravallion (2004) find no evidence of poverty traps in Russia and Hungary in the 1990s. Likewise, in a parametric analysis using consumption data, Jalan \& Ravallion (2004) find no evidence of a poverty trap in southern China in the late 1980s. ${ }^{3}$ These findings are consistent with the idea that poverty traps are not ubiquitous but rather are tied to multiple market failures that likely vary in intensity over space and time.

\section{$4 \quad$ Policy implications}

The poverty trap hypothesis is fundamental to development policy not only because the existence of poverty traps provides a moral imperative for intervention, but also because the nature of the poverty traps and the mechanism(s) that give rise to it must guide the design of any such intervention. Two major policy implications of the poverty traps hypothesis conclude this discussion.

First, there is overwhelming evidence that poverty traps exist, of both the single and multiple equilibria varieties. Efforts to address the root multiple market failures may therefore yield considerable dividends for populations that confront a prospective poverty trap. Consequently, there are a range of current empirical research efforts focused on credit or insurance programs that address multiple financial market failures, on safety net programs that protect assets, and on social protection schemes, child sponsorship programs, and education, health, nutrition and sanitation interventions that accelerate or protect investments in human capital. Similarly, there is interest in efforts to fundamentally change systems that perpetuate discrimination and foster single equilibrium poverty traps for subpopulations defined by immutable traits such as gender, race, or country of origin. There is substantial scope in using innovative empirical techniques to better identify poverty traps and evaluate programs that combat extreme pervasive poverty.

Second, while many high-profile development initiatives in recent years implicitly rest on a foundational theory of poverty traps' existence, it is important to continuously test the veracity of this assumption and of the impacts of interventions aimed at remediating the posited causal mechanism(s) that create the trap. The Millennium Villages Project (MVP), for example, follows Sachs' (2005) argument for large-scale, multi-sector development interventions to help rural Africans break free of poverty traps. But MVP did not incorporate a rigorous evaluation plan, making it difficult to assess whether Sachs' diagnosis was correct or the resulting intervention design was cost-effective. By contrast, BRAC's celebrated Graduation and Targeting the Ultra-Poor programs similarly explicitly rest on the

\footnotetext{
3 The difference between Jalan and Ravallion (2002) and their (2004) paper using the same region and data is that the earlier paper accounts for geographic externalities whereas the latter paper considers only returns to wealth at the farm-household level.
} 
hypothesis that by providing a multi-dimensional "big push" over a limited period of time the program can break the poorest villagers free from a poverty trap. A careful six country study of the Graduation design found large and persistent gains across a suite of ten outcome indicators even after beneficiaries exited the program (Banerjee et al. 2015). Bandiera et al. (2015) likewise find the combination of assets and skills transfers enables the poor to overcome financial market failures that otherwise trap them in low-return, seasonal casual wage labor; indeed the poor's gains generate positive spillovers for the non-poor leading to broader-based growth stimulated by poverty reduction.

The Thousand Days movement -- which aims to focus attention and investments on improving health and nutrition during the roughly one thousand days from the onset of a woman's pregnancy until her child's second birthday - likewise follows directly from the hypothesis that individual children can follow any of several path dynamics with very strong history-dependence in their human capital accumulation over the life course. Indeed, heavily researched early childhood investments have been shown to have pronounced effects preventing irreversible loss of cognitive, physical and sociocultural capacity and delivering instead improved adult education, productivity and pro-social behavioral impacts (Bhutta et al. 2013, Heckman 2006, Hoddinott et al. 2008, Maluccio et al. 2009).

The common denominator to such programs is that in the face of poverty traps, small adjustments often fail to move people out of low-level dynamic equilibria unless they happen to be carefully targeted at precisely the context-specific mechanism and threshold that trap people in poverty. Rather, systems must change, major positive shocks must occur, or both. ${ }^{4}$ And in the absence of systemic change, recurring adverse shocks only drive more people more deeply into the trap (Alderman et al. 2006). For both economic and moral reasons, ongoing interrogation of the poverty traps hypothesis and rigorous evaluation of interventions aimed at addressing traps' underlying causal mechanisms remain high priority research topics for economists and other social scientists.

\section{References}

Acemoglu D, Johnson S, Robinson JA. 2001. The colonial origins of comparative development: An empirical investigation. American Economic Review. 91:1369-1401

Adato M, Carter MR, May J. 2006. Exploring poverty traps and social exclusion in South Africa using qualitative and quantitative data. Development Studies. 42(2):226-47

Aizer A, Currie J. 2014. The intergenerational transmission of inequality: Maternal disadvantage and health at birth. Science. 344(6186):856-61

Alderman H, Hoddinott J, Kinsey B. 2006. Long term consequences of early childhood malnutrition. Oxf. Econ. Pap. 58(3):450-74

Almond D, Currie J. 2011. Killing me softly: The fetal origins hypothesis. Journal of Economic Perspectives. 25(3):153-72

Almond D, Edlund L, Palme M. 2009. Chernobyl's subclinical legacy: Prenatal exposure to

${ }^{4}$ While far beyond the scope of this paper, these same issues are central to debates around affirmative action programs and other social interventions aimed at corrective structural disadvantage (Coate \& Loury 1993, Holzer \& Neumark 2000). 
radioactive fallout and school outcomes in Sweden. Quarterly Journal of Economics. 124:1729-72

Antle JM, Stoorvogel JJ, Valdivia RO. 2006. Multiple equilibria, soil conservation investments, and the resilience of agricultural systems. Environment and Development Economics. 11(04):477-417

Antman F, McKenzie D. 2007. Poverty traps and nonlinea income dynamics with measurement error and individual heterogeneity. Journal of Development Studies. 43(6):1057-83

Azariadis C, Stachurski J. 2005. Poverty Traps, Vol. 1a. in P. Aghion and S. Durlauf (eds), Handbook of Economic Growth. North Holland, Netherlands: Elsevier Science Publishing

Baland JM, Platteau JP. 1996. Halting Degradation of Natural Resources: Is There a Role for Rural Communities? Rome, Italy: Food and Agriculture Organization.

Bandiera O, Burgess R, Das N, Gulesci S, Rasul I, Sulaimany M. 2015. The Misallocation of Labor in Village Economies $\boldsymbol{Q}$. London School of Economics working paper.

Banerjee A, Duflo E, Goldberg N, Karlan D, Osei R, et al. 2015. A multifaceted program causes lasting progress for the very poor: Evidence from six countries. Science. 348(6236):1260799.1-99

Banerjee A, Iyer L. 2005. History, institutions, and economic performance: The legacy of colonial land tenure systems in India. American Economic Review. 95(4):1190-1214

Banerjee A, Mullainathan S. 2010. The shape of temptation: Implications for the economic lives of the poor. NBER Working Paper No. w15973.

Barrett CB. 2005. Rural poverty dynamics: development policy implications. Agricultural Economics. 32(s1):45-60

Barrett, CB. 2014. Assisting the escape from persistent ultra-poverty in rural Africa. In WP Falcon, RL Naylor (eds) Frontiers in Food Policy: Perspectives on sub-Sabaran Africa. Palo Alto Stanford Center on Food Security and the Environment.

Barrett CB, Arcese P. 1998. Wildlife harvest in integrated conservation and development projects: Linking harvest to household demand, agricultural production, and environmental shocks in the Serengeti. Land Economics. 74(4):449-465

Barrett CB, Bachke ME, Bellemare MF, Michelson HC, Narayanan S, Walker TF. 2012. Smallholder Participation in Contract Farming: Comparative Evidence from Five Countries. World Development. 40(4):715-30

Barrett CB, Bevis LEM. 2015. The Reinforcing Feedback Between Low Soil Fertility and Chronic Poverty. Nature Geoscience. Advance access published November 23, 2015 doi:10.1038/ngeo2591

Barrett CB, Carter MR. 2013. The economics of poverty traps and persistent poverty: Empirical and policy implications. Journal of Development Studies. 49(7):976-90

Barrett CB, Carter MR, Ikegami M. 2008. Poverty traps and social protection. SSRN 1141881

Barrett CB, Marenya PP, McPeak J, Minten B, Murithi F, et al. 2006. Welfare dynamics in rural Kenya and Madagascar. Journal of Development Studies. 42.2: 248-277

Barrett CB, Reardon T, Webb P. 2001. Nonfarm income diversification and household livelihood strategies in rural Africa: concepts, dynamics, and policy implications. Food Policy. 26(4):315-31

Barrett CB, Santos P. 2014. The impact of changing rainfall variability on resourcedependent wealth dynamics. Ecological Economics. 105(C):48-54

Barrett CB, Swallow BM. 2006. Fractal poverty traps. World Development. 34(1):1-15

Barro RJ, Sala-i-Martin X. 2004. Economic Growth. MIT Press 
Baulch B, Hoddinott J. 2000. Economic mobility and poverty dynamics in developing countries. Journal of Development Studies. 36(6):1-24

Bazzi, S. 2015. Wealth Heterogeneity and the Income Elasticity of Migration. Manuscript, Boston University.

Beaman, L. and Magruder, J., 2012. Who gets the job referral? Evidence from a social networks experiment. American Economic Review, pp.3574-3593.

Bertrand M, Mullainathan S. 2004. Are Emily and Greg more employable than Lakisha and Jamal? A field experiment on labor market discrimination. American Economic Review. 94(4): 991-1013

Besley T. 1995. Nonmarket institutions for credit and risk sharing in low-income countries. Journal of Economic Perspectives. 9(3):115-127

Bhalotra S, Rawlings S. 2013. Gradients of the intergenerational transmission of health in developing countries. ReStat. 95(2):660-72

Bharadwaj P, Lundborg P, Rooth D-O. 2015. Birth weight in the long run. NBER Working Paper No. w21354

Bhutta ZA, Das JK, Rizvi A, Gaffey MF, Walker N, et al. 2013. Evidence-based interventions for improvement of maternal and child nutrition: What can be done and at what cost? The Lancet. 382(9890):452-77

Bliss C, Stern N. 1978. Productivity, wages, and nutrition. Journal of Development Economics. 5(4): 331-398

Bloom DE, Canning D, Sevilla J. 2003. Geography and poverty traps. Journal of Economic Growth. 8:355-78

Bloom DE, Sachs JD, Collier P, Udry C. 1998. Geography, demography, and economic growth in Africa. Brookings Papers on Economic Activity. 1998(2):207

Bonds MH, Keenan DC, Rohani P, Sachs JD. 2010. Poverty trap formed by the ecology of infectious diseases. Proceedings of the Royal Society of London B: Biological Sciences. 277(1685):1185-92

Bowles S, Durlauf SN, Hoff K. 2006. Poverty Traps. Princeton: Princeton University Press

Breiman L. 2001. Random Forests. Machine Learning. 45(1):5-32

Bryan G, Chowdhury S, Mobarak AM. 2014. Underinvestment in a profitable technology: The case of seasonal migration in Bangladesh. Econometrica. 82(5):1671-1748

Calvo-Armengol A, Jackson MO. 2015. The effects of social networks on employment and inequality. American Economic Review. 94:426-54

Carter MR. 2010. Environment, technology, and the social articulation of risk in West African agriculture. Econ. Dev. Cult. Change. 45(3):557-90

Carter MR, Barrett CB. 2006. The economics of poverty traps and persistent poverty: An asset-based approach. Journal of Development Studies. 42(2):178-99

Carter MR, Little PD, Mogues T, Negatu W. 2007. Poverty traps and natural disasters in Ethiopia and Honduras. World Development. 35(5):835-56

Carter MR, Lybbert TJ. 2012. Consumption versus asset smoothing: testing the implications of poverty trap theory in Burkina Faso. Journal of Development Economics. 99(2):255-64

Carter MR, May J. 2001. One kind of freedom: Poverty dynamics in post-apartheid South Africa. World Development. 29:1987-2006

Chantarat S, Barrett CB. 2011. Social network capital, economic mobility and poverty traps. $J$ Econ Inequal. 10(3):299-342

Chantarat S, Mude AG, Barrett CB, Turvey CG. 2015. Welfare impacts of index insurance in the presence of a poverty trap. Unpublished manuscript.

Chay K, Munshi K. 2011. Slavery's legacy: Black mobilization in the postbellum south. 


\section{Manuscript, Brown University}

Chen S, Ravallion M. 2010. The developing world is poorer than we thought, but no less successful in the fight against poverty. Quarterly Journal of Economics. 125(4):1577-1625

Coate S, Loury GC. 1993. Will affirmative-action policies eliminate negative stereotypes? The American Economic Review. 83(5): 1220-40

Conley TG, Udry C. 2010. Learning about a new technology: Pineapple in Ghana. American Economic Review. 100(1):35-69

Conti G, Heckman J, Urzua S. 2010. The education-health gradient. AER. 100(2):234-38

Dasgupta P. 1993. An Inquiry Into Well-Being and Destitution. Oxford University Press, USA

Dasgupta P. 1997. Nutritional status, the capacity for work, and poverty traps. Journal of Econometrics. 77(1):5-37

Dasgupta P, Ray D. 1986. Inequality as a determinant of malnutrition and unemployment: theory. The Economic Journal, 96(384):1011-1034

Dasgupta P, Ray D. 1987. Inequality as a determinant of malnutrition and unemployment: Policy. The Economic Journal. 97(385):177

Deaton A. 2013. The Great Escape. Princeton: Princeton University Press

Dell M. 2010. The persistent effects of Peru's mining Mita. Econometrica. 78(6):1863-1903

Dercon S. 1998. Wealth, risk and activity choice: cattle in Western Tanzania. Journal of Development Economics. 55(1):1-42

Durlauf SN. 1996. On the convergence and divergence of growth rates. Economic Journal. 106(437):1016-8

Durlauf SN, Johnson PA. 1995. Multiple regimes and cross-country growth behaviour. J. Appl. Econ. 10:365-84

Easterly W, Levine R. 1997. Africa's growth tragedy: Policies and ethnic divisions. Quarterly Journal of Economics. 112(4):1203-50

Fafchamps M, Pender J. 2012. Precautionary saving, credit constraints, and irreversible investment: Theory and evidence from Serniarid India. Journal of Business \& Economic Statistics. 15(2):180-94

Fang H, Loury GC. 2005. "Dysfunctional Identities" Can Be Rational. American Economic Review. 95(2):104-11.

Feder G, Just RE, Zilberman D. 1985. Adoption of agricultural innovations in developing countries: A survey. Econ. Dev. Cult. Change. 33(2): 255-298.

Fogel RW. 2004. The Escape From Hunger and Premature Death, 1700-2100. Cambridge, UK: Cambridge University Press

Foster AD, Rosenzweig MR. 2003. Economic growth and the rise of forests. Quarterly Journal of Economics. 118(2): 601-637

Gallup JL, Sachs JD, Mellinger AD. 1999. Geography and economic development. International Regional Science Review. 22(2):179-232

Galor O. 1996. Convergence? Inferences from theoretical models. Economic Journal. 106(437): 1056-1069.

Galor O, Zeira J. 1993. Income distribution and macroeconomics. The Review of Economic Studies. 60(1): 35-52.

Garg T. 2015. Public health effects of ecosystem degradation: Evidence from deforestation in Indonesia. Working Paper, Lafayette College

Giesbert L, Schindler K. 2012. Assets, shocks, and poverty traps in rural Mozambique. World Development. 40(8):1594-1609

Green A. 2011. Institutions matter, but in surprising ways: New evidence on institutions in Africa. Kyklos. 64(1):87-105 
Green A, Moser C. 2013. Do property rights institutions matter at the local level? Evidence from Madagascar. Journal of Development Studies. 49(1):95-109

Hansen BE. 2000. Sample splitting and threshold estimation. Econometrica. 68(3): 575-603

Hardin G. 1968. The tragedy of the commons. Science. 162(3859): 1243-1248

Haushofer J, Fehr E. 2014. On the psychology of poverty. Science. 344(6186):862-67

Heckman JJ. 2006. Skill formation and the economics of investing in disadvantaged children. Science. 312(5782):1900-1902

Hoddinott J. 2006. Shocks and their consequences across and within households in rural Zimbabwe. Journal of Development Studies. 42(2):301-21

Hoddinott J, Maluccio JA, Behrman JR, Flores R, Martorell R. 2008. Effect of a nutrition intervention during early childhood on economic productivity in Guatemalan adults. Lancet. 371(9610):411-16

Holzer H, Neumark D. 2000. Assessing Affirmative Action. Journal of Economic Literature. 38(3): 483-568

Iyer L. 2010. Direct versus indirect colonial rule in India: Long-term consequences. Review of Economics and Statistics. 92(4): 693-713

Jalan J, Ravallion M. 2004. Household income dynamics in rural China. In Insurance Against Poverty. Ed. S. Dercon. Oxford University Press

Jalan J, Ravallion M. 2002. Geographic poverty traps? A micro model of consumption growth in rural China. J. Appl. Econ. 17(4):329-46

Janzen SA, Carter MR. 2013. After the drought: The impact of microinsurance on consumption smoothing and asset protection. National Bureau of Economic Research working paper 19702.

Janzen S, Carter MR, Ikegami M. 2012. Valuing asset insurance in the presence of poverty traps. Working Paper. 1-31

Keesing F, Belden LK, Daszak P, Dobson A, Harvell CD, et al. 2010. Impacts of biodiversity on the emergence and transmission of infectious diseases. Nature. 468(7324):647-52

Kraay A, McKenzie D. 2014. Do poverty traps exist? Assessing the evidence. Journal of Economic Perspectives. 28(3):127-48

Krishna A, Lumonya D, Markiewicz M, Mugumya F, Kafuko A, Wegoye J. 2006. Escaping poverty and becoming poor in 36 villages of Central and Western Uganda. Journal of Development Studies. 42(2):346-70

Kwak S, Smith SC. 2013. Regional agricultural endowments and shifts of poverty trap equilibria: Evidence from Ethiopian panel data. Journal of Development Studies. 49(7):95575

Laajaj R. 2015. Closing one's eyes on a gloomy future: Psychological causes and economic consequences. Working Paper, Paris School of Economics

Loh WY. 2002. Regression trees with unbiased variable selection and interaction detection. Statistica Sinica. 12:361-86

Lokshin M, Ravallion M. 2004. Household income dynamics in two transition economies. Studies in Nonlinear Dynamics and Econometrics. 8(3):1558-3708

Loury GC. 1981. Intergenerational Transfers and the Distribution of Earnings. Econometrica. 49(4):843

Lybbert TJ, Barrett CB, Desta S, Coppock DL. 2004. Stochastic wealth dynamics and risk management among a poor population. Economic Journal. 114:750-77

Lybbert TJ, Just DR, Barrett CB. 2013. Estimating risk preferences in the presence of bifurcated wealth dynamics: can we identify static risk aversion amidst dynamic risk 
responses? European Review of Agricultural Economics. 40(2):361-77

Maccini SL, Yang D. 2008. Under the Weather: Health, Schooling, and Economic Consequences of Early-Life Rainfall. American Economic Review. 99(3): 1006-1026

Maluccio JA, Hoddinott J, Behrman JR, Martorell R, Quisumbing AR, Stein AD. 2009. The impact of improving nutrition during early childhood on education among Guatemalan adults. Economic Journal. 119(537):734-63

Mani A, Mullainathan S, Shafir E, Zhao J. 2013. Poverty Impedes Cognitive Function. Science. 341(6149):976-80

Marenya PP, Barrett CB. 2009a. Soil quality and fertilizer use rates among smallholder farmers in western Kenya. Agricultural Economics. 40(5):561-72

Marenya PP, Barrett CB. 2009b. State conditional fertilizer yield response on western Kenyan farms. American Journal of Agricultural Economics. 991-1006

McKenzie DJ, Woodruff C. 2006. Do entry costs provide an empirical basis for poverty traps? Evidence from Mexican microenterprises. Econ. Dev. Cult. Change. 55(1):3-42

McPeak J. 2004. Contrasting income shocks with asset shocks: livestock sales in northern Kenya. Oxf. Econ. Pap. 56(2):263-84

Michelson H, Muñiz M, DeRosa K. 2013. Measuring socio-economic status in the Millennium Villages: The role of asset index choice. Journal of Development Studies. 49(7):917-35

Mogues T, Carter MR. 2005. Social capital and the reproduction of economic inequality in polarized societies. J Econ Inequal. 3(3):193-219

Montgomery JD. 1991. Social networks and labor-market outcomes: Toward an economic analysis. American Economic Review.. 81:1408-18

Moser CM, Barrett CB. 2006. The complex dynamics of smallholder technology adoption: the case of SRI in Madagascar. Agricultural Economics. 35(3):373-88

Moya A. 2012. Violence, emotional distress and induced changes in risk aversion among the displaced population in Colombia. Pacific Development Economics Conference, University of California, Davis

Munshi K. 2011. Strength in Numbers: Networks as a Solution to Occupational Traps. Review of Economic Studies. 78(3):1069-1101

Munishi K, and M. Rosenzweig 2015. Insiders and Outsiders: Local Ethnic Politics and Public Goods Provision. NBER Working Paper no. 21720.

Naschold F. 2012. "The poor stay poor": Household asset poverty traps in rural semi-arid India. World Development. 40(10):2033-43

Naschold F. 2013. Welfare dynamics in Pakistan and Ethiopia - Does the estimation method matter? Journal of Development Studies. 49(7):936-54

Naschold F, Barrett CB. 2011. Do short-term observed income changes overstate structural economic mobility? Oxford Bulletin of Economics and Statistics. 73(5):705-17

Ngonghala CN, Pluciński MM, Murray MB, Farmer PE, Barrett CB, et al. 2014. Poverty, disease, and the ecology of complex systems. PLOS Biol. 12(4):e1001827-29

Nunn N. 2007. Historical legacies: A model linking Africa's past to its current underdevelopment. Journal of Development Economics. 83(1):157-75

Nunn N. 2009. The importance of history for economic development. NBER Working Paper w14899

Ostrom E. 1990. Governing the Commons. Cambridge, UK: Cambridge University Press

Quah D. 1993. Galton's Fallacy and tests of the convergence hypothesis. Scandinavian Journal of Economics. 95(4):427

Quisumbing AR, Baulch B. 2013. Assets and poverty traps in rural Bangladesh. Journal of 
Development Studies. 49(7):898-916

Ravallion M. 2013. How long will it take to lift one billion people out of poverty? World Bank Research Observer. 28(2): 139-158.

Ray D, Streufert PA. 1993. Dynamic equilibria with unemployment due to undernourishment. Econ Theory. 3(1):61-85

Reardon T, Barrett CB, Berdegué JA, Swinnen JFM. 2009. Agrifood industry transformation and small farmers in developing countries. World Development. 37(11):1717-27

Rosenzweig MR, Binswanger HP. 1993. Wealth, Weather Risk, and the Composition and Profitability of Agricultural Investments. Economic Journal. 103(416): 56-78

Rosenzweig MR, Wolpin KI. 1993. Credit market constraints, consumption smoothing, and the accumulation of durable production assets in low-income countries: Investments in bullocks in India. Journal of Political Economy. 101(2): 223-244

Sachs J. 2005. The End of Poverty. New York: Penguin Books

Sachs J. 2014. The case for aid. Foreign Policy, January 21, 2014

Santos P, Barrett CB. 2006. Heterogeneous wealth dynamics: On the roles of risk and ability. $S A G A$ Working Paper

Santos P, Barrett CB. 2011. Persistent poverty and informal credit. Journal of Development Economics. 96(2):337-47

Schilbach, F. 2015. Alcohol and self control: A field experiment in India. MIT.

Schofield, H., 2014. The Economic Costs of Low Caloric Intake: Evidence from India. Harvard University.

Shah A K, Mullainathan S, Shafir E. 2012. Some consequences of having too little. Science, 338(6107): 682-685.

Shah AK, Shafir E, Mullainathan S. 2015. Scarcity frames value. Psychological Science. 26(4):111

Shepherd KD, Soule MJ. 1998. Soil fertility management in west Kenya: dynamic simulation of productivity, profitability and sustainability at different resource endowment levels. Agriculture, Ecosystems \& Environment. 71(1-3):131-45

Shively GE, Barbier EB, Burgess JC. 2001. Agricultural change, rural labor markets, and forest clearing: An illustrative case from the Philippines. Land Economics. 77(2):268-84

Stephens EC, Nicholson CF, Brown DR, Parsons D, Barrett CB, et al. 2012. "Modeling the impact of natural resource-based poverty traps on food security in Kenya: The Crops, Livestock and Soils in Smallholder Economic Systems (CLASSES) model." Food Security. 4(3):423-39

Stiglitz JE. 1976. The efficiency wage hypothesis, surplus labour, and the distribution of income in LDCs. Oxf. Econ. Papers. 28(2): 185-207

Tan CM. 2010. No one true path: Uncovering the interplay between geography, institutions, and fractionalization in economic development. J. Appl. Econ. 25(7):1100-1127

Thaler RH, Sunstein CR. 2009. Nudge: Improving Decisions About Health, Wealth, and Happiness. 2008. Newhaven, CT: Yale

Thomas A-C, Gaspart F. 2015. Does poverty trap rural Malagasy households? World Development. 67:490-505

Tittonell P, Giller KE. 2013. When yield gaps are poverty traps: The paradigm of ecological intensification in African smallholder agriculture. Field Crops Research. 143:76-90

Toth R. 2014. Traps and Thresholds in Pastoralist Mobility. American Journal of Agricultural Economics. 97(1):aau064-aau332

Vanderpuye-Orgle J, Barrett CB. 2009. Risk management and social visibility in Ghana. African Development Review. 21(1):5-35 
Victora CG, Adair L, Fall C, Hallal PC, Martorell R, et al. 2008. Maternal and child undernutrition: consequences for adult health and human capital. Lancet. 371(9609):34057

Whitehead A. 2006. Persistent poverty in North East Ghana. Journal of Development Studies. 42(2):278-300

Zimmerman FJ, Carter MR. 2003. Asset smoothing, consumption smoothing and the reproduction of inequality under risk and subsistence constraints. Journal of Development Economics. 71(2):233-60 